\title{
DIRETORES DE ESCOLA E GESTÃO DEMOCRÁTICA NA REGIÃO DO
}

\author{
ABC PAULISTA
}

(1) Prof. Dr. Paulo Sérgio Garcia (garciaps@ usp.br), (2) Prof. Dr. Leandro Campi Prearo, (3) Prof. Dra. Maria do Carmo Romero, (4) Prof. Dr. Marcos Sidnei Bassi (1, 2, 3 e 4: Universidade Municipal de São Caetano do Sul - Observatório da Educação do Grande ABC)

\section{Resumo:}

O Brasil enfrenta o desafio de promover a qualidade na escola pública brasileira e, neste processo, entre muitas coisas, o diretor escolar tem um papel relevante. Trata-se de um profissional que influencia a escola e os resultados dos alunos por meio de seu perfil e das formas de condução da gestão democrática. Este estudo tem o objetivo identificar e analisar as características dos diretores escolares da Região do Grande ABC Paulista e, paralelamente, investigar como os processos de gestão democrática têm sido conduzidos nas escolas públicas da mesma região. Um estudo de caso foi utilizado para coletar informações, inicialmente, no Censo Escolar de 2013 sobre o perfil do diretor e sobre os processos da gestão democrática. Esses achados foram contextualizados a partir de entrevistas com diretores $(\mathrm{N}=26)$ das unidades escolares da região. Os resultados mostraram que a maioria dos diretores são mulheres, acima dos 40 anos idade, formadas em pedagogia, em instituições privadas, cursos presenciais, com experiência de mais de cinco anos. Em relação à gestão escolar democrática, constatou-se que se trata ainda de um processo frágil, mais fortalecido no discurso das pessoas do que da concretude das realizações escolares. A gestão democrática é ainda muito mais um símbolo inspirador do que um marco que incita à ação. Os resultados deste estudo podem ser utilizados para fomentar discussões entre especialistas e gestores, bem como nos cursos de formação de diretores.

Palavras-chave: Perfil profissional. Diretor escolar. Gestão democrática.

\section{SCHOOL PRINCIPALS AND DEMOCRATIC MANAGEMENT IN THE ABC PAULISTA REGION}

\section{Abstract:}

Brazil faces the challenge of promoting quality in public schools and in the process, among many things, the principal plays an important role. This is a professional who influence the school and student achievements through his profile and democratic management. This study aims to identify and analyze the characteristics of school principals of the metropolitan area of São Paulo (Região do Grande ABC Paulista) and, in parallel, to investigate how the democratic management processes have been conducted in public schools in the same region. A case study was used to collect information, initially from School Census 2013 on principal profile, and on democratic management. These findings were contextualized using interviews with school principals $(\mathrm{N}=26)$. The results showed that the majority of principals are women, above 40 years old, majored in pedagogy, in private institutions, in traditional courses, with experience of more than five years. Regarding the democratic school management, it was found that it is still a fragile process that is much more concrete in the principals' discourse than in their daily practices. Democratic management has been much more an inspiring symbol than a mechanism to encourage daily action. These results can be used to foster discussions between specialists in education and school principals as well as in the principal pre-service education.

Key-words: Professional profile. School Principals. Democratic management.

\section{Introdução}

O Brasil atravessa o desafio de melhorar a escola pública brasileira. Um processo laborioso, desafiador e complexo, considerando que a qualidade educacional depende de fatores extraescolares: o fator espaço social e a participação e as obrigações do Estado; e intraescolares: as condições de oferta do ensino, o fator escola, a gestão e organização do trabalho escolar, o fator professor e aluno (DOURADO; OLIVEIRA, 2009). 
No processo de qualidade educacional, o diretor de escola assume papel importante. Nas últimas décadas, várias transformações têm ocorrido na profissão deste profissional, originando maiores responsabilidades. Ele atua no planejamento, na mobilização e orientação das pessoas (pais de alunos, professores), na gestão pedagógica e financeira, no desenvolvimento profissional dos professores e na gestão dos resultados, incluindo o processo de monitoramento dos alunos.

Trata-se de um profissional que influencia, direta e indiretamente, a escola (PEREDA; LUCCHESI, 2015), tem como foco de atuação a condução da gestão escolar (BLOOM et al, 2014), com destaque para a gestão democrática (GD) como uma das mais importantes características de liderança (LÜCK, 2009).

Os diretores que atuam na educação brasileira possuem os mais variados percursos formativos (formação inicial e continuada), experiências profissionais distintas, foram selecionados para a profissão de forma diferente e possuem conhecimentos e habilidades diversas para lidar e conduzir a gestão democrática (conselho de escola, projeto político pedagógico, participação da comunidade, grêmio estudantil).

A identificação do perfil do diretor e a compreensão sobre suas formas de condução do processo gestão democrática são tarefas complexas, mais importantes para contribuir com o processo de qualidade do sistema educacional brasileiro. Neste sentido, este estudo procura identificar e analisar as características (perfil) dos diretores escolares da Região do Grande ABC Paulista e, paralelamente, investigar como os processos de gestão democrática têm sido conduzidos nas escolas públicas da mesma região.

\section{Perfil do diretor}

Os estudos sobre o diretor de escola, entre outras coisas, têm se centrado sobre o perfil deste profissional (GRACINDO, 2009; BÉTEILLE et al, 2011; DOBBIE; FRYER, 2013) na sociedade moderna e os desafios da gestão democrática para a democratização da escola e da sociedade (VIANNA, 1986; VEIGA, 1997; DOURADO, 2000; BORDIGNON; GRACINDO, 2001; PARO, 2006; LÜCK, 2008; GRACINDO, 2009).

Em relação ao perfil, Grancido (2009) discute sobre suas características e sobre o tipo de formação adequada na contemporaneidade. A mesma autora, reconhecendo a experiência como condição essencial para o exercício profissional das funções de magistério, salienta que a profissão do diretor deverá ser assumida por um professor. Para tal, no entanto, ela situa a importância de as licenciaturas praticarem uma formação, entre outras coisas, relacionada à compreensão da instituição escolar de forma administrativa e pedagógica, das políticas educacionais e do processo de gestão educativa.

Nas sinalizações de Cury (2001, p. 16), o gestor deverá ser um administrador da educação e da educação escolar, onde os processos gerais de formação serão iguais a todo e qualquer educador. No entanto, o gestor deverá adquirir conhecimentos específicos que o habilite para outras atividades pertinentes ao trabalho escolar. 
Alguns estudos procuraram analisar como o diretor tem influenciado o processo de aprendizado dos alunos, cotidianamente, em sua atuação, por meio, entre outras, da gestão pedagógica e financeira, da mobilização e orientação de pessoas e do controle dos resultados escolares. Em uma pesquisa realizada pela Fundação Itaú Social, em parceria com a London School of Economics, 2014, procurando identificar em países desenvolvidos e subdesenvolvidos as boas práticas dos diretores no trabalho, foi revelado que o Brasil estava em penúltimo lugar no indicador geral relacionado às práticas gerenciais. $\mathrm{O}$ estudo mostrou ainda que a gestão de pessoas foi a pior dimensão avaliada, sobretudo nas escolas públicas.

Dobbie e Fryer (2013), no contexto americano, analisaram o perfil gerencial de diretores como fatores explicativos do aprendizado dos estudantes. Foi identificado, como fatores que influenciavam positivamente o aprendizado, o feedback para o professor, o uso dos resultados de avaliação dos jovens, o engajamento dos pais com as atividades da escola, os processo de tutorias para alunos, horas efetivas de trabalho em matemática e língua inglesa, foco no ensino e na aprendizagem e altas expectativas em relação ao comportamento e a disciplina de todos os estudantes. Em outro estudo, Grisson, Loeb e Master (2013), também nos EUA, identificaram, como fatores positivos, o feedback para os professores, a implementação e a utilização de avaliações e a criação de um programa educacional. No mesmo sentido, Fullan (2013) sinalizou que este profissional exerce uma liderança em movimento, orientando e mobilizando pessoas em função de objetivos para trazer melhorias para a escola. Em outro trabalho, o mesmo autor sugeriu que o diretor é um agente de mudanças contagiosas (FULLAN, 2014).

Marioni, Freguglia e Costa, (2014) analisaram o desempenho dos diretores de 2005 a 2008 e evidenciaram efeitos positivos em relação à confiança dos professores nesses profissionais; à atenção deste no que diz respeito às normas administrativas e sua capacidade de motivar as pessoas para inovações. Pereda e Lucchesi (2015) situaram que alunos das redes municipais e estaduais possuem maior desempenho em escolas onde o diretor está no exercício da função em um período entre 5 a 15 anos. Para que ele influencie positivamente os jovens é necessário tempo para, entre outras coisas, conhecer a escola, aprender sobre a gestão escolar e inovar. Além da permanência no cargo, a experiência do diretor (administrativa e pedagógica) tem influência positiva no desempenho dos alunos (BÉTEILLE; KALOGRIDES; LOEB, 2011).

\section{Gestão Democrática}

A Gestão Democrática (GD), no nível macrossocial, relaciona-se ao processo de construção e democratização da sociedade brasileira e, no micro, a uma forma de gerir a escola, possibilitando transparência e a construção da democracia. Trata-se de um sistema, que não é criado e conduzido somente pela imposição da legislação, mas sim construído a partir da participação efetiva de todos os atores da unidade escolar. 
A GD, grosso modo, organiza o funcionamento da escola pública em relação aos componentes administrativos, financeiros, políticos, culturais, sociais, artísticos e pedagógicos. Tal organização tem a finalidade de tratar com transparência todas as ações, possibilitando a comunidade escolar compreender os processos por meio da discussão e do diálogo. Sua missão se relaciona à melhoria da qualidade da escola pública, a partir da participação dos agentes. De acordo com Cury (2002, p. 173) "a gestão democrática da educação é, ao mesmo tempo, transparência e impessoalidade, autonomia e participação, liderança e trabalho coletivo, representatividade e competência".

Para Dourado (2000, p. 79), a gestão democrática é um processo que inclui aprendizagem e luta política que não se limita a prática educativa, "mas vislumbra, nas especificidades dessa prática social e de sua relativa autonomia, a criação de canais de efetiva participação e aprendizado do "jogo" democrático e, consequentemente, do repensar das estruturas de poder que permeiam as relações sociais e, no seio dessas, as práticas educativas”. Para Veiga (2004, p. 19) tal processo implica na reflexão sobre a estrutura de poder da escola: "A socialização do poder propicia a prática da participação coletiva, que atenua o individualismo; da reciprocidade, que elimina a exploração; da solidariedade, que supera a opressão; da autonomia, que anula a dependência de órgãos intermediários que elaboram políticas educacionais das quais a escola é mera executora."

A Constituição Federal, de 1988, no artigo 206, instituiu a GD como um dos princípios da educação brasileira. A Lei de Diretrizes e Bases da Educação Nacional (LDBEN/96), no artigo 14, fez indicações, ainda que superficiais, sobre a GD, mostrando que os sistemas de ensino definirão as normas da gestão democrática do ensino público na educação básica, baseado "na participação dos profissionais da educação na elaboração do projeto pedagógico da escola e na participação das comunidades escolar e local em conselhos escolares ou equivalentes". Mais recentemente, também o Plano Nacional de Educação (PNE), artigo 2, Lei 13.005, 25 de junho de 2014, aponta como diretriz para a educação nacional a gestão democrática. A meta 19 do plano "visa assegurar condições, no prazo de dois anos, para a efetivação da gestão democrática da educação" (Plano Nacional de Educação, 2014).

Araújo (2000) sinaliza quatro elementos constitutivos da gestão democrática: a participação, o pluralismo, a autonomia e a transparência. Desses, destaca-se o processo de participação, que implica os vários atores, incluindo a comunidade escolar, na construção da autonomia e da democratização da escola. Tal participação está relacionada, entre outras coisas, com as fases de planejamento e avaliação da instituição. No entanto, para a viabilização da GD, é preciso que processos e instâncias deliberativas sejam criados e estabelecidos, baseados na descentralização das decisões e ações, na participação e na transparência. Neste sentido, a GD prevê canais de participação, coletivos e de responsabilidade compartilhada, onde se destacam a participação da comunidade, a autonomia escolar, o financiamento das escolas, o conselho de classe, o grêmio estudantil, a assembleia geral da escola, a escolha de dirigentes, o conselho escolar e a construção do Plano Político Pedagógico (PPP). 
Desses canais, destacam-se os três últimos. O primeiro é a escolha dos diretores de escola está comumente baseada: a) na indicação do profissional, geralmente realizada pelo chefe do poder executivo local, ou por parlamentares ou dirigentes educacionais, vinculada às questões político-partidárias, sendo que o indicado pode não ser um profissional do campo educacional; b) no concurso público onde, geralmente, há um exame de seleção para a verificação da capacidade técnica do profissional; e c) na eleição direta, realizada pelos membros da unidade escolar e da comunidade com a utilização de algum tipo de pleito. Existem ainda algumas configurações mistas de seleção, utilizando duas ou mais dessas formas.

Em um dos primeiros trabalhos no Brasil, realizando uma análise sobre como a forma de escolha do diretor influencia o desempenho dos alunos, Barros e Mendonça (1998), utilizando dados do Censo Escolar, PNAD e SAEB, compararam o rendimento dos jovens e as diferentes formas de seleção de diretores, entre 1983 e 1993. Apesar de o estudo mostrar que existe impacto significativo no desempenho, tal efeito explicava apenas metade de melhoria que foi observada.

No que diz respeito às evidências sobre efeitos diretos da seleção de diretores sobre os alunos, um estudo realizado a partir de dados da Prova Brasil (2005-2011) revelou que a rotatividade dos diretores nas escolas públicas é prejudicial para os jovens e, ao mesmo tempo, que a indicação política de gestores tem efeito negativo no IDEB. Neste caso, reduzindo, em média, 11 pontos na escala SAEB (MIRANDA; PAZELLO, 2014).

O segundo é o conselho escolar, com representação de diferentes segmentos sociais (sistema de ensino, escola, poder público, sociedade civil, alunos, comunidade), tem caráter deliberativo e fiscalizador de recursos. Trata-se de um colegiado que envolve a descentralização do poder, trazendo a legitimidade às ações do diretor.

Os conselhos buscam o desenvolvimento da participação, a corresponsabilidade dos membros da unidade e compromisso com a escola. Eles são, como afirmam Azevedo e Gracindo (2005), instrumentos importantes para a desejada prática democrática. O conselho representa os interesses da escola, por meio da comunidade escolar e local. Sua atuação deve acontecer em harmonia com os interesses escolares e o trabalho dos gestores. Trata-se de auxiliar nas tomadas de decisões de natureza administrativa, financeira e político-pedagógicas (GRACINDO, 2009).

O terceiro canal importante de participação é o PPP da escola. Tal documento é previsto pelos artigos 12 e 14, inciso I, da LDBEN/96. Trata-se de um instrumento para estabelecer uma visão de conjunto e um norte para a instituição, contando, para tal, com a contribuição de todos da escola e da comunidade. Este documento orienta todas as práticas e os projetos educacionais, demonstrando a missão e os valores da escola e o tipo de formação pretendida. Mostra-se, neste sentido, a identidade da instituição. Para Veiga (2003), o PPP se constitui, a partir da realidade escolar, de forma participativa e coletiva, como o compromisso de formar o cidadão. A mesma autora trabalha com a ideia de o PPP ser visto sob uma perspectiva de inovação emancipatória e um processo de vivência democrática. O Projeto deve estar 
preocupado em estabelecer uma forma de "organização do trabalho pedagógico que desvele os conflitos e as contradições, buscando eliminar as relações competitivas, corporativas e autoritárias, rompendo com a rotina do mando pessoal e racionalizado da burocracia e permitindo relações horizontais no interior da escola" (VEIGA, 2004, p.38).

\section{A Região do Grande ABC Paulista}

A região do Grande $A B C$ apresenta características peculiares como indica o Quadro 01:

\begin{tabular}{|c|c|c|c|c|c|c|c|}
\hline Quadro 01: Características demográficas da região. \\
\hline Município & Santo André São Bernardo & São Caetano & Diadema & Mauá & Ribeirão Pires & Rio Grande da Serra \\
\hline População & 704.942 & 805,895 & 156.362 & 406.718 & 444.136 & 118.871 & 47.142 \\
\hline Área territorial Km2 & 175,781 & 409,478 & 15,33 & 30,796 & 61,866 & 99,119 & 36,341 \\
\hline PIB (milhões) & 17.664 .718 & 36.337 .338 & 11.762 .744 & 11.786 .624 & 7.633 .782 & 1.978 .256 & 529.413 \\
\hline Posição do PIB & $33^{\mathrm{a}}$ & $14^{\mathrm{a}}$ & $48^{\mathrm{a}}$ & $47^{\mathrm{a}}$ & $79^{\mathrm{a}}$ & $287^{\mathrm{a}}$ & $816^{\mathrm{a}}$ \\
\hline IDHM 2010 & $0,815\left(8^{\circ}\right)$ & $0,805\left(16^{\circ}\right)$ & $0,862\left(1^{\circ}\right)$ & $0,757\left(184^{\circ}\right)$ & $0,766\left(134^{\circ}\right)$ & $0,784\left(58^{\circ}\right)$ & $0,749\left(245^{\circ}\right)$ \\
\hline Renda Familiar (\$) & 1.499 & 1.394 & 2.349 & 917 & 815 & 974 & 747 \\
\hline
\end{tabular}

Fonte: IBGE - 2011: Elaboração dos autores.

A região localiza-se no estado de São Paulo e é composta por sete municípios: Santo André (SA), São Bernardo do Campo (SBC), São Caetano do Sul (SCS), Diadema (D), Mauá (M), Ribeirão Pires (RP) e Rio Grande da Serra (RGS). Sua área atinge $635 \mathrm{~km}^{2}$, com população de 2,5 milhões de habitantes e um PIB industrial aproximado de $\mathrm{R} \$ 27$ bilhões, considerado o segundo do estado e o terceiro do país.

Os municípios do grande ABC, em geral, possuem posições elevadas no Índice de Desenvolvimento Humano Municipal (IDH-M). São Caetano é a cidade que tem o maior IDH-M e a renda familiar (R\$ $2.349,00)$. Nos municípios, a população possui, em média, 10 anos de estudo.

Em relação ao número de escolas e matrículas do Ensino Fundamental, de acordo com os dados do Censo Escolar de 2013, os Quadros 02 e 03 sintetizam a realidade da região:

Quadro 02, número de escolas:

\begin{tabular}{|c|c|c|c|c|c|c|c|c|c|}
\hline \multicolumn{10}{|c|}{ Quadro 02: Número de escolas do grande ABC - 2013} \\
\hline \multirow{2}{*}{\multicolumn{2}{|c|}{ Número de escolas }} & \multicolumn{7}{|c|}{ Cidades } & \multirow[b]{2}{*}{ GABC } \\
\hline & & SA & SBC & SCS & DIA & MAU & $\mathbf{R P}$ & RGS & \\
\hline Municipal & E.F. I e II & 51 & 72 & 20 & 27 & 16 & 9 & 3 & 198 \\
\hline Estadual & E.F. I e II & 84 & 73 & 10 & 56 & 64 & 29 & 11 & 327 \\
\hline
\end{tabular}

Dados do Observatório de Educação do grande ABC: Elaboração dos autores.

Quadro 03, número de matrículas:

\begin{tabular}{|} 
Quadro 03: Número de matrículas do grande $\mathrm{ABC}-2013$ \\
\hline \multicolumn{1}{|c|}{ Número de matrículas } & \multicolumn{9}{|c|}{ Cidades } \\
\cline { 3 - 12 } & & SA & SBC & SCS & DIA & MAU & RP & RGS & GABC \\
\hline Municipal & E.F. I e II & 18.482 & 40.755 & 11.220 & 12.956 & 3.214 & 3.420 & 176 & $\mathbf{9 0 . 2 2 3}$ \\
\hline Estadual & E.F. I e II & 41.990 & 42.515 & 2.783 & 39.302 & 44.389 & 9.696 & 5.091 & $\mathbf{1 8 5 . 7 6 6}$ \\
\hline
\end{tabular}

Dados do Observatório de Educação do grande ABC: Elaboração dos autores.

A região contava em 2013 com 198 escolas, 90.223 matrículas e 7.397 professores no Ensino Fundamental municipal e 327 instituições, 13.778 professores e 185.766 alunos matriculados na rede estadual (Observatório de Educação do Grande ABC, de 2015). 
A infraestrutura escolar avançou muito nas últimas décadas, superando de longe a dura realidade brasileira. Tomando como base a escala desenvolvida por Soares et al (2013), a infraestrutura da região está no nível avançado (74\%). Tal situação indica uma realidade bem diferente da brasileira. No entanto, é preciso considerar que a infraestrutura é tributária dos projetos pedagógicos da escola e das ações de ensino dos professores (GARCIA et al, 2014).

\section{Metodologia}

Este estudo apresenta duas questões importantes: a primeira procura identificar e analisar o perfil (as características) dos diretores escolares de Ensino Fundamental (esfera estadual e municipal) da Região do Grande ABC Paulista, parte da área metropolitana de São Paulo e, a segunda, busca investigar como esses profissionais lidam e conduzem a gestão democrática, sobretudo o conselho de escola, o projeto político pedagógico, a participação da comunidade e as formas de seleção dos diretores.

A escolha da região prendeu-se ao fato de ela ser uma das mais ricas do país, contando com o IDH-M médio, em 2010, de, aproximadamente, 0,792. A população apresentava, em média, 10 anos de estudos e as escolas possuíam infraestrutura adequada para a aprendizagem dos alunos (SOARES, et al, 2013).

O tratamento metodológico, a partir de um estudo de caso exploratório (YIN, 1993), contou com a abordagem quantitativa e qualitativa. No primeiro caso, os dados foram coletados a partir do Censo Escolar de 2013, disponível no portal do Instituto Nacional de Estudos e Pesquisas (http://portal.inep.gov.br/basica-censo) e no Observatório de Educação da Região do Grande ABC. Em razão do tamanho da amostra, apenas sete municípios), optou-se por uma avaliação exploratória dos dados com a utilização de quadros e tabelas, sem a realização de testes estatísticos. Tal situação teve o objetivo de identificar as regularidades, similaridades e diferenças entre as cidades, detalhando o perfil dos diretores que atuavam nas escolas da região e, paralelamente, as questões da gestão democrática (conselho de escola, formas de seleção de diretores; projeto político pedagógico, participação da comunidade).

As categorias deste estudo foram definidas previamente. Quanto ao perfil do diretor foram coletadas informações sobre gênero, raça, idade, formação inicial (tipo e natureza de instituição da formação inicial, modalidade de formação), formação contínua em pós-graduação, atuação (experiência, tempo como diretor na escola que atua e carga de trabalho semanal). Em relação à gestão democrática foram recolhidas evidências sobre o conselho de escola (a presença ou não deste colegiado na escola, número de reuniões anual, caracterização dos representantes); sobre a forma de seleção de diretor na escola; sobre o projeto político pedagógico (forma de elaboração); sobre a participação da comunidade na unidade escolar (utilização dos espaços para atividades comunitárias, organização de eventos da escola destinados à comunidade (cursos, práticas esportivas, palestras), utilização das instalações e recursos da escola pela comunidade, organização de campanhas de solidariedade propostas pela comunidade). 
$\mathrm{Na}$ abordagem qualitativa, os resultados encontrados, em relação à gestão democrática, especificamente sobre o conselho de escola e o projeto político pedagógico, foram contextualizados a partir das perspectivas dos diretores de escolas da região, por meio de uma análise também exploratória.

Foram selecionados, ao acaso, 10 diretores de cada cidade, em 2014, das esferas municipal e estadual. No entanto, somente responderam positivamente para participar do estudo quatro de Santo André, dois da esfera municipal e dois da estadual; quatro de São Bernardo, dois e dois; seis de São Caetano, quatro e dois; três de Diadema, um e dois. As cidade de Mauá, Ribeirão Pires e Rio Grande da Serra tiveram a participação de e três diretores, todos da rede estadual.

Assim a amostra do estudo é formada por 26 diretores. As entrevistas com esses profissionais tinham caráter aberto e coletaram informações, a partir de suas perspectivas, buscando aprofundar nos dados encontrados em relação ao: 1) conselho de escola e 2) projeto político pedagógico. Quanto à primeira categoria foi investigada a formação do conselho, sua função e os principais temas tratados nas reuniões. $\mathrm{Na}$ segunda, foi analisada a influência do PPP sobre as decisões na escola.

Os dados advindos das entrevistas foram analisados com a abordagem da teoria fundamentada (CORBIN e STRAUSS, 1998). A partir de uma investigação temática, os dados das declarações dos diretores foram decompostos, visando agrupar aqueles temas mais recorrentes e mais significativos. Tal situação reforça o entendimento sobre os depoimentos. A partir desta codificação e análise, os dados foram filtrados com o uso de códigos e descritores, possibilitando evidenciar as diferenças, regularidades e similaridades. Este processo de redução e conversão dos dados possibilitou a criação de outras categorias e uma maior compreensão sobre elas.

\section{Resultados}

Inicialmente, são apresentados os resultados do perfil do diretor de escola caracterizado a partir das categorias gênero, raça, idade, formação inicial e contínua e atuação. Esta caracterização permitiu, em seguida, a apresentação das questões relacionadas à gestão democrática. Por fim, os dados foram contextualizados na perspectiva daqueles que estavam envolvidos nos processos, os diretores de escolas.

\section{Caracterização do perfil do diretor da região do grande $\mathrm{ABC}$}

O perfil do diretor de escola é retratado nos Tabelas por meio de análise uma exploratória. Os dados foram baseados no Censo Escolar do ano de 2013.

Quanto ao gênero, a Tabela 01 sintetiza os resultados:

Tabela 01: Caracterização do gênero dos diretores da Região do Grande ABC - 2013.

\begin{tabular}{|c|c|c|c|c|c|c|c|c|c|c|c|c|c|c|}
\hline \multirow[b]{3}{*}{ (M)unicipal/ } & \multicolumn{14}{|c|}{ Municípios } \\
\hline & & & & & & & & & & & & & & \\
\hline & $\mathbf{M}$ & $\mathbf{E}$ & $\mathbf{M}$ & $\mathbf{E}$ & $\mathbf{M}$ & $\mathbf{E}$ & $\mathbf{M}$ & $\mathbf{E}$ & $\mathbf{M}$ & $\mathbf{E}$ & $\mathbf{M}$ & $\mathbf{E}$ & $\mathbf{M}$ & \\
\hline
\end{tabular}




\begin{tabular}{c|c|c|c|c|c|c|c|c|c|c|c|c|c|c} 
(E)stadual & & & & & & & & & & & & & & \\
\hline Feminino & 100 & 84 & 91 & 85 & 100 & 90 & 100 & 91 & 100 & 78 & 100 & 86 & - & 90 \\
\hline Masculino & 0 & 16 & 9 & 15 & 0 & 10 & 0 & 9 & 0 & 22 & 0 & 14 & - & 10
\end{tabular}

Fonte: Elaboração dos autores.

O grupo de diretores do Ensino Fundamental da Região do Grande ABC é formado em sua imensa maioria por mulheres, tanto na esfera municipal como estadual. Os poucos diretores homens envolvidos com o ensino neste nível estão mais localizados na esfera estadual.

Em relação à raça, a Tabela 02 mostra os resultados encontrados:

Tabela 02: Caracterização da raça dos diretores da Região do Grande ABC -2013.

\begin{tabular}{|c|c|c|c|c|c|c|c|c|c|c|c|c|c|c|}
\hline \multirow[b]{3}{*}{$\begin{array}{c}\text { (M)unicipal/ } \\
\text { (E)stadual }\end{array}$} & \multicolumn{14}{|c|}{ Municípios } \\
\hline & \multicolumn{2}{|c|}{$\begin{array}{l}\text { SA } \\
(\%)\end{array}$} & \multicolumn{2}{|c|}{$\begin{array}{l}\text { SBC } \\
(\%)\end{array}$} & \multicolumn{2}{|c|}{$\begin{array}{l}\text { SCS } \\
(\%)\end{array}$} & \multicolumn{2}{|c|}{$\begin{array}{l}\text { DIA } \\
(\%)\end{array}$} & \multicolumn{2}{|c|}{$\begin{array}{c}\text { MAU } \\
(\%)\end{array}$} & \multicolumn{2}{|c|}{$\begin{array}{l}\text { RP } \\
(\%)\end{array}$} & \multicolumn{2}{|c|}{$\begin{array}{l}\text { RGS } \\
(\%)\end{array}$} \\
\hline & $\mathbf{M}$ & $\mathbf{E}$ & $\mathbf{M}$ & $\mathbf{E}$ & $\mathbf{M}$ & $\mathbf{E}$ & $\mathbf{M}$ & $\mathbf{E}$ & $\mathbf{M}$ & $\mathrm{E}$ & $\mathbf{M}$ & $\mathbf{E}$ & M & $\mathrm{E}$ \\
\hline Branco (a) & 89 & 91 & 82 & 80 & 95 & 70 & 66 & 82 & 100 & 76 & 60 & 79 & - & 80 \\
\hline Pardo (a) & 11 & 7 & 11 & 11 & 5 & 30 & 27 & 13 & 0 & 18 & 20 & 18 & - & 10 \\
\hline Preto (a) & 0 & 1 & 7 & 3 & 0 & 0 & 7 & 5 & 0 & 1 & 0 & 3 & - & 10 \\
\hline Amarelo (a) & 0 & 1 & 0 & 6 & 0 & 0 & 0 & 0 & 0 & 3 & 20 & 0 & - & 0 \\
\hline Indígena & 0 & 0 & 0 & 0 & 0 & 0 & 0 & 0 & 0 & 2 & 0 & 0 & - & 0 \\
\hline
\end{tabular}

Fonte: Elaboração dos autores.

Em relação à raça, a grande maioria dos diretores se considerou branco, tanto na esfera municipal como estadual. Há poucos profissionais que se consideram pardos e outra parte menor pretos. A idade desses profissionais foi caracterizada na Tabela 03:

Tabela 03: Caracterização da idade dos diretores da Região do Grande ABC - 2013.

\begin{tabular}{|c|c|c|c|c|c|c|c|c|c|c|c|c|c|c|}
\hline \multirow[b]{3}{*}{$\begin{array}{c}\text { (M)unicipal/ } \\
\text { (E)stadual }\end{array}$} & \multicolumn{14}{|c|}{ Municípios } \\
\hline & \multicolumn{2}{|c|}{$\begin{array}{l}\text { SA } \\
(\%)\end{array}$} & \multicolumn{2}{|c|}{$\begin{array}{l}\text { SBC } \\
(\%)\end{array}$} & \multicolumn{2}{|c|}{$\begin{array}{l}\text { SCS } \\
(\%)\end{array}$} & \multicolumn{2}{|c|}{$\begin{array}{l}\text { DIA } \\
(\%)\end{array}$} & \multicolumn{2}{|c|}{$\begin{array}{c}\text { MAU } \\
(\%)\end{array}$} & \multicolumn{2}{|c|}{$\begin{array}{l}\text { RP } \\
(\%)\end{array}$} & \multicolumn{2}{|c|}{$\begin{array}{c}\text { RGS } \\
(\%)\end{array}$} \\
\hline & $\mathbf{M}$ & $\mathbf{E}$ & $\mathbf{M}$ & $\mathbf{E}$ & $\mathbf{M}$ & $\mathbf{E}$ & $\mathbf{M}$ & $\mathbf{E}$ & $\mathbf{M}$ & $\mathbf{E}$ & $\mathbf{M}$ & $\mathrm{E}$ & $\mathbf{M}$ & $\mathrm{E}$ \\
\hline Até 24 anos & 2 & 0 & 0 & 3 & 0 & 0 & 0 & 6 & 0 & 3 & 0 & 7 & - & 0 \\
\hline De 25 a 29 & 2 & 1 & 6 & 2 & 0 & 0 & 0 & 5 & 0 & 2 & 0 & 4 & - & 0 \\
\hline De 30 a 39 & 9 & 5 & 26 & 7 & 6 & 0 & 21 & 9 & 100 & 8 & 20 & 0 & - & 0 \\
\hline De 40 a 49 & 48 & 40 & 44 & 36 & 53 & 30 & 36 & 38 & 0 & 45 & 20 & 57 & - & 75 \\
\hline De 50 a 54 & 27 & 26 & 10 & 27 & 18 & 30 & 29 & 20 & 0 & 29 & 0 & 21 & - & 13 \\
\hline 55 ou mais & 12 & 28 & 14 & 25 & 23 & 30 & 14 & 22 & 0 & 13 & 60 & 11 & - & 12 \\
\hline
\end{tabular}

Fonte: Elaboração dos autores.

Nesta região, na esfera municipal, a grande maioria dos diretores está com idade acima dos 40 anos. Em algumas cidades, mais de 40\% da força de trabalho está acima dos 50 anos (Santo André, São Caetano, Diadema e Ribeirão Pires). Na esfera estadual, a situação é um pouco mais crítica em relação a esse número. Existem mais diretores com idade acima de 50 anos.

Depreende-se de tal fato implicações negativas para o campo educacional das cidades, pois, em breve, uma grande parte desses profissionais estará aposentada e deverá ser substituída por outros diretores sem experiência profissional equivalente.

Em relação à formação inicial dos diretores, as Tabelas 04, 05, 06 e 07 sintetizam os dados:

Tabela 04: Caracterização da formação dos diretores da Região do Grande ABC - 2013.

\begin{tabular}{|c|c|c|c|c|c|c|}
\hline \multicolumn{7}{|c|}{ Municípios } \\
\hline $\begin{array}{l}\text { SA } \\
(\%)\end{array}$ & $\begin{array}{c}\text { SBC } \\
(\%)\end{array}$ & $\begin{array}{l}\text { SCS } \\
(\%)\end{array}$ & $\begin{array}{c}\text { DIA } \\
\text { (\%) }\end{array}$ & $\begin{array}{c}\text { MAU } \\
(\%)\end{array}$ & $\begin{array}{l}\text { RP } \\
(\%)\end{array}$ & $\begin{array}{c}\text { RGS } \\
(\%)\end{array}$ \\
\hline
\end{tabular}




\begin{tabular}{c|c|c|c|c|c|c|c|c|c|c|c|c|c|c} 
(M)unicipal/ (E)stadual & $\mathbf{M}$ & $\mathbf{E}$ & $\mathbf{M}$ & $\mathbf{E}$ & $\mathbf{M}$ & $\mathbf{E}$ & $\mathbf{M}$ & $\mathbf{E}$ & $\mathbf{M}$ & $\mathbf{E}$ & $\mathbf{M}$ & $\mathbf{E}$ & $\mathbf{M}$ & $\mathbf{E}$ \\
\hline Ensino Superior Pedagogia & 82 & 58 & 81 & 64 & 63 & 60 & 80 & 58 & 100 & 51 & 80 & 69 & - & 70 \\
\hline Ens.Sup./outras Licenciaturas & 11 & 33 & 12 & 25 & 25 & 40 & 7 & 33 & 0 & 32 & 20 & 21 & - & 20 \\
\hline Ensino Superior - outros & 7 & 9 & 7 & 11 & 11 & 0 & 13 & 9 & 0 & 17 & 0 & 10 & - & 10
\end{tabular}

Fonte: Elaboração dos autores.

Quanto ao tipo de instituição:

Tabela 05: Caracterização do tipo de instituição de formação dos diretores da Região do Grande ABC - 2013.

\begin{tabular}{|c|c|c|c|c|c|c|c|c|c|c|c|c|c|c|}
\hline \multirow[b]{3}{*}{ (M)unicipal/(E)stadual } & \multicolumn{14}{|c|}{ Municípios } \\
\hline & \multicolumn{2}{|c|}{$\begin{array}{l}\text { SA } \\
(\%)\end{array}$} & \multicolumn{2}{|c|}{$\begin{array}{c}\text { SBC } \\
(\%)\end{array}$} & \multicolumn{2}{|c|}{$\begin{array}{l}\text { SCS } \\
(\%)\end{array}$} & \multicolumn{2}{|c|}{$\begin{array}{c}\text { DIA } \\
(\%)\end{array}$} & \multicolumn{2}{|c|}{$\begin{array}{c}\text { MAU } \\
(\%)\end{array}$} & \multicolumn{2}{|c|}{$\begin{array}{l}\text { RP } \\
(\%)\end{array}$} & \multicolumn{2}{|c|}{$\begin{array}{c}\text { RGS } \\
(\%)\end{array}$} \\
\hline & $\mathbf{M}$ & $\mathbf{E}$ & $\mathbf{M}$ & $\mathrm{E}$ & $\mathbf{M}$ & $\mathbf{E}$ & $\mathbf{M}$ & $\mathbf{E}$ & $\mathbf{M}$ & $\mathbf{E}$ & $\mathbf{M}$ & $\mathbf{E}$ & $\mathbf{M}$ & $\mathbf{E}$ \\
\hline Pública federal & 0 & 0 & 1 & 1 & 0 & 0 & 7 & 3 & 0 & 0 & 0 & 0 & - & 0 \\
\hline Pública Estadual & 7 & 5 & 6 & 0 & 16 & 0 & 0 & 2 & 0 & 3 & 0 & 0 & - & 10 \\
\hline Pública Municipal & 9 & 3 & 6 & 3 & 0 & 11 & 13 & 0 & 0 & 2 & 20 & 0 & - & 0 \\
\hline Privada & 84 & 92 & 87 & 96 & 84 & 89 & 80 & 95 & 100 & 95 & 80 & 100 & - & 90 \\
\hline
\end{tabular}

Fonte: Elaboração dos autores.

Quanto à natureza da instituição:

Tabela 06: Caracterização da natureza da instituição de formação dos diretores da Região do Grande ABC - 2013.

\begin{tabular}{|c|c|c|c|c|c|c|c|c|c|c|c|c|c|c|}
\hline \multirow[b]{3}{*}{ (M)unicipal/(E)stadual } & \multicolumn{14}{|c|}{ Municípios } \\
\hline & \multicolumn{2}{|c|}{$\begin{array}{c}\text { SA } \\
(\%)\end{array}$} & \multicolumn{2}{|c|}{$\begin{array}{c}\text { SBC } \\
(\%)\end{array}$} & \multicolumn{2}{|c|}{$\begin{array}{l}\text { SCS } \\
(\%)\end{array}$} & \multicolumn{2}{|c|}{$\begin{array}{l}\text { DIA } \\
(\%)\end{array}$} & \multicolumn{2}{|c|}{$\begin{array}{c}\text { MAU } \\
(\%)\end{array}$} & \multicolumn{2}{|c|}{$\begin{array}{l}\text { RP } \\
(\%)\end{array}$} & \multicolumn{2}{|c|}{$\begin{array}{c}\text { RGS } \\
(\%)\end{array}$} \\
\hline & $\mathbf{M}$ & E & $\mathbf{M}$ & $\mathbf{E}$ & $\mathbf{M}$ & $\mathbf{E}$ & $\mathbf{M}$ & $\mathbf{E}$ & M & $\mathbf{E}$ & M & $\mathbf{E}$ & $\mathbf{M}$ & $\mathbf{E}$ \\
\hline Faculdade Isolada & 21 & 36 & 44 & 45 & 37 & 40 & 60 & 32 & 0 & 41 & 100 & 55 & - & 30 \\
\hline Centro Universitário & 52 & 26 & 13 & 13 & 5 & 10 & 7 & 12 & 100 & 18 & 0 & 10 & - & 10 \\
\hline Universidade & 27 & 36 & 40 & 42 & 53 & 50 & 33 & 56 & 0 & 39 & 0 & 28 & - & 50 \\
\hline Não se aplica & 0 & 2 & 3 & 0 & 5 & 0 & 0 & 0 & 0 & 2 & 0 & 7 & - & 10 \\
\hline
\end{tabular}

Fonte: Elaboração dos autores.

Em relação à modalidade do curso realizado na formação inicial:

Tabela 07: Caracterização modalidade do curso de formação dos diretores da Região do Grande ABC -2013.

\begin{tabular}{|c|c|c|c|c|c|c|c|c|c|c|c|c|c|c|}
\hline \multirow[b]{3}{*}{ (M)unicipal/(E)stadual } & \multicolumn{14}{|c|}{ Municípios } \\
\hline & \multicolumn{2}{|c|}{$\begin{array}{c}\text { SA } \\
(\%)\end{array}$} & \multicolumn{2}{|c|}{$\begin{array}{c}\text { SBC } \\
(\%)\end{array}$} & \multicolumn{2}{|c|}{$\begin{array}{l}\text { SCS } \\
(\%)\end{array}$} & \multicolumn{2}{|c|}{$\begin{array}{c}\text { DIA } \\
(\%)\end{array}$} & \multicolumn{2}{|c|}{$\begin{array}{c}\text { MAU } \\
(\%)\end{array}$} & \multicolumn{2}{|c|}{$\begin{array}{l}\text { RP } \\
(\%)\end{array}$} & \multicolumn{2}{|c|}{$\begin{array}{c}\text { RGS } \\
(\%)\end{array}$} \\
\hline & $\mathbf{M}$ & $\mathbf{E}$ & $\mathbf{M}$ & $\mathbf{E}$ & $\mathbf{M}$ & $\mathbf{E}$ & $\mathbf{M}$ & $\mathrm{E}$ & $\mathbf{M}$ & $\mathrm{E}$ & $\mathbf{M}$ & $\mathrm{E}$ & $\mathbf{M}$ & $\mathbf{E}$ \\
\hline Presencial & 100 & 95 & 99 & 99 & 95 & 100 & 100 & 96 & 100 & 98 & 100 & 97 & - & 100 \\
\hline Semi-presencial & 0 & 5 & 0 & 1 & 0 & 0 & 0 & 2 & 0 & 0 & 0 & 3 & - & 0 \\
\hline A Distância & 0 & 0 & 1 & 0 & 5 & 0 & 0 & 2 & 0 & 2 & 0 & 0 & - & 0 \\
\hline
\end{tabular}

Fonte: Elaboração dos autores.

Na região do Grande ABC, a maioria dos diretores que está atuando nas escolas é formada em Pedagogia, em cursos de nível superior. No entanto, há um grupo com formação em outras licenciaturas. A quase totalidade desses profissionais foi formada em instituições privadas. Quanto à natureza da formação, eles frequentaram cursos de formação inicial em Universidades, Centros Universitários e Faculdades isoladas. Os percursos formativos utilizados pela mairoria estavam relacionados a cursos presenciais, muito pelo fato de a maioria ter sido formada antes do crescimento explosivo da educação a distância no Brasil.

Quanto à formação contínua desses diretores, a Tabela 08 sintetiza os resultados:

Tabela 08: Caracterização da formação contínua dos diretores da Região do Grande ABC - 2013. 


\begin{tabular}{|c|c|c|c|c|c|c|c|c|c|c|c|c|c|c|}
\hline \multirow[b]{2}{*}{$\begin{array}{c}\text { (M)unicipal/(E)stadua } \\
1\end{array}$} & \multicolumn{2}{|c|}{$\begin{array}{l}\text { SA } \\
(\%)\end{array}$} & \multicolumn{2}{|c|}{$\begin{array}{l}\text { SBC } \\
(\%)\end{array}$} & \multicolumn{2}{|c|}{$\begin{array}{l}\text { SCS } \\
(\%)\end{array}$} & \multicolumn{2}{|c|}{$\begin{array}{l}\text { DIA } \\
(\%)\end{array}$} & \multicolumn{2}{|c|}{$\begin{array}{c}\text { MAU } \\
(\%)\end{array}$} & \multicolumn{2}{|c|}{$\begin{array}{l}\text { RP } \\
(\%)\end{array}$} & \multicolumn{2}{|c|}{$\begin{array}{l}\text { RGS } \\
(\%)\end{array}$} \\
\hline & $\mathbf{M}$ & $\mathbf{E}$ & $\mathbf{M}$ & $\mathbf{E}$ & $\mathbf{M}$ & $\mathbf{E}$ & $\mathbf{M}$ & $\mathbf{E}$ & $\mathbf{M}$ & $\mathbf{E}$ & $\mathbf{M}$ & $\mathbf{E}$ & $\mathbf{M}$ & $\mathbf{E}$ \\
\hline Atualização $-180 \mathrm{~h}$ & 5 & 11 & 6 & 5 & 16 & 10 & 27 & 14 & 0 & 13 & 0 & 11 & - & 0 \\
\hline Especialização $-360 \mathrm{~h}$ & 82 & 60 & 61 & 56 & 63 & 60 & 60 & 70 & 100 & 65 & 60 & 46 & - & 90 \\
\hline Mestrado & 4 & 6 & 9 & 3 & 5 & 0 & 0 & 4 & 0 & 6 & 0 & 4 & - & 0 \\
\hline Doutorado & 0 & 1 & 1 & 0 & 0 & 0 & 0 & 0 & 0 & 0 & 0 & 0 & - & 0 \\
\hline Não fez/Completou & 9 & 22 & 23 & 36 & 16 & 30 & 13 & 12 & 0 & 16 & 40 & 39 & - & 10 \\
\hline
\end{tabular}

Fonte: Elaboração dos autores.

Em geral, esses profissionais, tanto pertencentes ao município como ao estado, possuiam algum tipo de pós-graduação, indicando a preocupação com a formacao continuada. A especialização de 360 horas foi a mais utilizada, talvez por escolha pessoal ou pela oportunidade concedida pela rede de ensino. Observando os dados é fato que existem poucos diretores com o título de mestre. Tal situação pode ser vista como uma oportunidade para os municípios garantir maior formação para esses diretores.

Em relação à experiência do diretor, o tempo de atuação em sua escola e sua carga horária semanal, as Tabelas 09,10 e 11 mostram os resultados:

Quanto à experiencia:

Tabela 09: Caracterização da experiência dos diretores da Região do Grande ABC - 2013.

\begin{tabular}{|c|c|c|c|c|c|c|c|c|c|c|c|c|c|c|}
\hline \multirow[b]{3}{*}{ (M)unicipal/(E)stadual } & \multicolumn{14}{|c|}{ Municípios } \\
\hline & \multicolumn{2}{|c|}{$\begin{array}{l}\text { SA } \\
(\%)\end{array}$} & \multicolumn{2}{|c|}{$\begin{array}{l}\text { SBC } \\
(\%)\end{array}$} & \multicolumn{2}{|c|}{$\begin{array}{l}\text { SCS } \\
(\%)\end{array}$} & \multicolumn{2}{|c|}{$\begin{array}{l}\text { DIA } \\
(\%)\end{array}$} & \multicolumn{2}{|c|}{$\begin{array}{c}\text { MAU } \\
(\%)\end{array}$} & \multicolumn{2}{|c|}{$\begin{array}{l}\text { RP } \\
(\%)\end{array}$} & \multicolumn{2}{|c|}{$\begin{array}{l}\text { RGS } \\
(\%)\end{array}$} \\
\hline & $\mathbf{M}$ & $\mathbf{E}$ & $\mathbf{M}$ & $\mathbf{E}$ & $\mathbf{M}$ & $\mathbf{E}$ & $\mathbf{M}$ & $\mathbf{E}$ & $\mathbf{M}$ & $\mathbf{E}$ & $\mathbf{M}$ & $\mathbf{E}$ & $\mathbf{M}$ & $\mathbf{E}$ \\
\hline $\begin{array}{l}\text { Há menos de } \\
\text { um ano }\end{array}$ & 9 & 5 & 10 & 11 & 5 & 10 & 7 & 3 & 0 & 2 & 20 & 4 & - & 10 \\
\hline De 1 a 5 & 58 & 21 & 18 & 23 & 34 & 10 & 79 & 23 & 0 & 17 & 40 & 26 & - & 20 \\
\hline De 5 a 10 & 20 & 30 & 38 & 27 & 22 & 40 & 0 & 35 & 100 & 37 & 20 & 26 & - & 40 \\
\hline De 10 a 15 & 9 & 25 & 17 & 17 & 5 & 20 & 7 & 19 & 0 & 18 & 0 & 26 & - & 10 \\
\hline De 15 a20 & 2 & 5 & 11 & 11 & 6 & 10 & 7 & 11 & 0 & 10 & 0 & 7 & - & 20 \\
\hline Há mais de 20 & 2 & 14 & 6 & 11 & 28 & 10 & 0 & 9 & 0 & 13 & 20 & 11 & - & 0 \\
\hline
\end{tabular}

Em relação ao tempo na direção daquela escola:

Tabela 10: Caracterização do tempo na direção em sua escola dos diretores da Região do Grande ABC - 2013.

\begin{tabular}{|c|c|c|c|c|c|c|c|c|c|c|c|c|c|c|}
\hline \multirow[b]{3}{*}{ (M)unicipal/(E)stadual } & \multicolumn{14}{|c|}{ Municípios } \\
\hline & \multicolumn{2}{|c|}{$\begin{array}{l}\text { SA } \\
(\%)\end{array}$} & \multicolumn{2}{|c|}{$\begin{array}{c}\text { SBC } \\
(\%)\end{array}$} & \multicolumn{2}{|c|}{$\begin{array}{l}\text { SCS } \\
(\%)\end{array}$} & \multicolumn{2}{|c|}{$\begin{array}{l}\text { DIA } \\
(\%)\end{array}$} & \multicolumn{2}{|c|}{$\begin{array}{c}\text { MAU } \\
(\%)\end{array}$} & \multicolumn{2}{|c|}{$\begin{array}{l}\text { RP } \\
(\%)\end{array}$} & \multicolumn{2}{|c|}{$\begin{array}{c}\text { RGS } \\
(\%)\end{array}$} \\
\hline & M & $\mathbf{E}$ & M & $\mathrm{E}$ & M & E & M & E & $\mathbf{M}$ & $\mathrm{E}$ & $\mathbf{M}$ & $\mathrm{E}$ & M & $\mathbf{E}$ \\
\hline Há menos de um ano & 16 & 13 & 34 & 29 & 11 & 50 & 20 & 9 & 0 & 15 & 40 & 17 & - & 10 \\
\hline De 1 a 5 & 69 & 44 & 24 & 27 & 74 & 10 & 73 & 38 & 100 & 27 & 40 & 34 & - & 50 \\
\hline De 5 a 10 & 11 & 28 & 21 & 24 & 10 & 20 & 7 & 30 & 0 & 39 & 20 & 31 & - & 30 \\
\hline De 10 a 15 & 4 & 8 & 11 & 14 & 0 & 10 & 0 & 18 & 0 & 14 & 0 & 14 & - & 10 \\
\hline De 15 a 20 & 0 & 5 & 7 & 0 & 0 & 10 & 0 & 5 & 0 & 3 & 0 & 4 & - & 0 \\
\hline Há mais de 20 & 0 & 2 & 3 & 6 & 5 & 0 & 0 & 0 & 0 & 2 & 0 & 0 & - & 0 \\
\hline
\end{tabular}

Fonte: Elaboração dos autores.

Quanto à carga horaria semanal de trabalho:

Tabela 11: Caracterização da carga horária semanal de trabalho dos diretores da Região do Grande ABC - 2013.

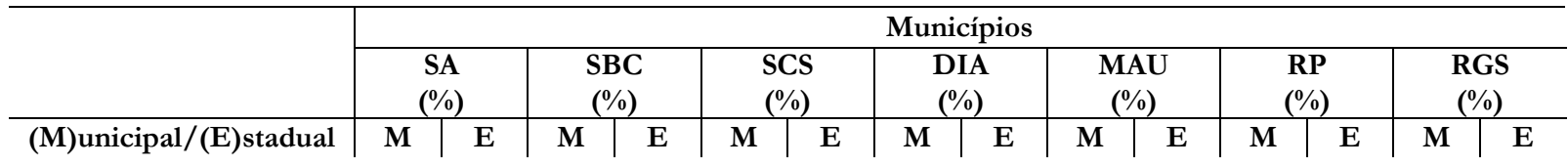




\begin{tabular}{c|c|c|c|c|c|c|c|c|c|c|c|c|c|c} 
Até 20 horas semanais & 2 & 0 & 0 & 0 & 0 & 0 & 0 & 0 & 0 & 0 & 0 & 0 & - & 0 \\
\hline Até $\mathbf{3 0}$ & 0 & 0 & 0 & 1 & 0 & 0 & 0 & 0 & 0 & 0 & 0 & 0 & - & 0 \\
\hline Até 40 & 89 & 75 & 91 & 72 & 21 & 50 & 86 & 86 & 100 & 73 & 100 & 96 & - & 90 \\
\hline Mais de 40 & 9 & 25 & 9 & 27 & 79 & 50 & 14 & 14 & 0 & 27 & 0 & 4 & - & 10
\end{tabular}

Fonte: Elaboração dos autores.

$\mathrm{Na}$ região, em geral, os diretores possuíam experiência na profissão. A grande maioria, exceto Santo André, Diadema e Riberião Pires, escolas municipais, possuía mais de cinco anos de experiência. Neste contexto, a maioria dos diretores tinha menos de 5 anos na mesma escola (exceto Diadema, Mauá e Ribeirão Pires, esfera estadual).

Em relação à carga de trabalho semanal desses profissionais, a maioria atuava até 40 horas semanais, não importando o tipo de esfera. Situação diferente encontrada na rede de ensino de São Caetano, onde alguns profissionais sinalizaram trabalhar mais 40 horas, tanto no município como no estado.

\section{Gestão Democrática}

Os resultados apresentam alguns elementos da gestão democrática (conselho de escola, seleção de diretores, projeto político pedagógico e participação da comunidade na escola) da região do grande ABC, das esferas municipal e estadual.

Quanto ao conselho escolar, os Quadros 04, na esfera estadual, e 05, na municipal, sintetizam os resultados:

\begin{tabular}{|c|c|c|c|c|c|c|c|c|c|c|c|c|c|c|}
\hline \multicolumn{15}{|c|}{ Quadro 04: Caracterização do conselho escolar esfera estadual dos municípios da Região do Grande ABC - 2013.} \\
\hline \multirow{3}{*}{$\begin{array}{c}\text { Esfera } \\
\text { Estadual }\end{array}$} & \multicolumn{14}{|c|}{ Cidade } \\
\hline & \multicolumn{2}{|c|}{ SA } & \multicolumn{2}{|c|}{ SBC } & \multicolumn{2}{|c|}{ SCS } & \multicolumn{2}{|c|}{ DIA } & \multicolumn{2}{|c|}{ MAU } & \multicolumn{2}{|c|}{ RP } & \multicolumn{2}{|c|}{ RGS } \\
\hline & $\begin{array}{c}\text { Uma/ } \\
\text { Duas } \\
(\%) \\
\end{array}$ & $\begin{array}{c}\text { Três/ } \\
\text { mais } \\
(\%) \\
\end{array}$ & $\begin{array}{c}\text { Uma/ } \\
\text { Duas } \\
(\%) \\
\end{array}$ & $\begin{array}{l}\text { Três/ } \\
\text { mais } \\
(\%) \\
\end{array}$ & $\begin{array}{c}\text { Uma/ } \\
\text { Duas } \\
(\%) \\
\end{array}$ & $\begin{array}{l}\text { Três/ } \\
\text { mais } \\
(\%) \\
\end{array}$ & $\begin{array}{c}\text { Uma/ } \\
\text { Duas } \\
(\%) \\
\end{array}$ & $\begin{array}{l}\text { Três/ } \\
\text { mais } \\
(\%) \\
\end{array}$ & $\begin{array}{c}\text { Uma/ } \\
\text { Duas } \\
(\%) \\
\end{array}$ & $\begin{array}{l}\text { Três/ } \\
\text { mais } \\
(\%) \\
\end{array}$ & $\begin{array}{c}\text { Uma/ } \\
\text { Duas } \\
(\%) \\
\end{array}$ & $\begin{array}{l}\text { Três/ } \\
\text { mais } \\
(\%) \\
\end{array}$ & $\begin{array}{c}\text { Uma/ } \\
\text { Duas } \\
(\%) \\
\end{array}$ & $\begin{array}{c}\text { Três/ } \\
\text { mais } \\
(\%)\end{array}$ \\
\hline $\begin{array}{l}\text { Reunião do } \\
\text { conselho }\end{array}$ & 4 & 96 & 7 & 93 & 10 & 90 & 12 & 88 & 10 & 90 & 3 & 97 & 0 & 100 \\
\hline \multirow{2}{*}{$\begin{array}{l}\text { Composição } \\
\text { do conselho } \\
\text { (professores) }\end{array}$} & Sim & Não & Sim & Não & Sim & Não & Sim & Não & Sim & Não & Sim & Não & Sim & Não \\
\hline & 100 & 0 & 100 & 0 & 100 & 0 & 100 & 0 & 97 & 3 & 100 & 0 & 100 & 0 \\
\hline Funcionários & 100 & 0 & 99 & 1 & 100 & 0 & 100 & 0 & 95 & 5 & 100 & 0 & 100 & 0 \\
\hline Alunos & 98 & 2 & 99 & 1 & 100 & 0 & 96 & 4 & 92 & 8 & 93 & 7 & 100 & 0 \\
\hline Pais & 100 & 0 & 100 & 0 & 100 & 0 & 100 & 0 & 97 & 3 & 100 & 0 & 100 & 0 \\
\hline
\end{tabular}

Fonte: Elaboração dos autores.

Todas as escolas dos sete municípios possuíam conselho de escola. A maioria delas realizou no ano de 2013 mais de três reuniões na unidade escolar. Existia, na composição deste colegiado, a participação de forma ampla de professores, funcionários, alunos e pais. Quanto à esfera municipal:

\begin{tabular}{|c|c|c|c|c|c|c|c|c|c|c|c|c|c|c|}
\hline \multirow{3}{*}{$\begin{array}{c}\text { Esfera } \\
\text { Municipal }\end{array}$} & \multicolumn{14}{|c|}{ Cidade } \\
\hline & \multicolumn{2}{|c|}{ SA } & \multicolumn{2}{|c|}{ SBC } & \multicolumn{2}{|c|}{ SCS } & \multicolumn{2}{|c|}{ DIA } & \multicolumn{2}{|c|}{ MAU } & \multicolumn{2}{|c|}{ RP } & \multicolumn{2}{|c|}{ RGS } \\
\hline & Uma/ & Três/ & Uma/ & Três/ & Uma/ & Três/ & Uma/ & Três/ & Uma/ & Três/ & Uma/ & Três/ & Uma/ & Três/ \\
\hline
\end{tabular}




\begin{tabular}{|c|c|c|c|c|c|c|c|c|c|c|c|c|c|c|}
\hline & $\begin{array}{c}\text { Duas } \\
(\%)\end{array}$ & $\begin{array}{c}\text { mais } \\
(\%)\end{array}$ & $\begin{array}{c}\text { Duas } \\
(\%)\end{array}$ & $\begin{array}{l}\text { mais } \\
(\%)\end{array}$ & $\begin{array}{c}\text { Duas } \\
(\%)\end{array}$ & $\begin{array}{c}\text { mais } \\
(\%)\end{array}$ & $\begin{array}{c}\text { Duas } \\
(\%)\end{array}$ & $\begin{array}{c}\text { mais } \\
(\%)\end{array}$ & $\begin{array}{c}\text { Duas } \\
(\%)\end{array}$ & $\begin{array}{c}\text { mais } \\
(\%)\end{array}$ & $\begin{array}{c}\text { Duas } \\
(\%)\end{array}$ & $\begin{array}{c}\text { mais } \\
(\%)\end{array}$ & $\begin{array}{c}\text { Duas } \\
(\%)\end{array}$ & $\begin{array}{c}\text { mais } \\
(\%)\end{array}$ \\
\hline $\begin{array}{c}\text { Reunião do } \\
\text { conselho }\end{array}$ & 2 & 98 & 3 & 97 & 71 & 28 & 7 & 93 & 0 & 100 & 0 & 100 & 0 & 100 \\
\hline \multirow{2}{*}{$\begin{array}{l}\text { Composição } \\
\text { do conselho } \\
\text { (professores) }\end{array}$} & Sim & Não & Sim & Não & Sim & Não & Sim & Não & $\mathrm{Sim}$ & Não & Sim & Não & Sim & Não \\
\hline & 98 & 2 & 100 & 0 & 100 & 0 & 100 & 0 & 100 & 0 & 100 & 0 & 100 & 0 \\
\hline Funcionários & 98 & 2 & 83 & 17 & 100 & 0 & 100 & 0 & 100 & 0 & 100 & 0 & 100 & 0 \\
\hline Alunos & 44 & 56 & 100 & 0 & 43 & 57 & 40 & 60 & 100 & 0 & 20 & 80 & 100 & 0 \\
\hline Pais & 96 & 4 & 100 & 0 & 100 & 0 & 100 & 0 & 100 & 0 & 100 & 0 & 100 & 0 \\
\hline
\end{tabular}

As escolas municipais dos sete municípios possuíam conselho de escola. A maioria delas realizou em 2013 mais de três reuniões. Somente a cidade de São Caetano realizou um número menor de reuniões. Existia a participação de forma ampla de professores, funcionários, alunos e pais no conselho, exceto na cidade de Santo André, São Caetano e Diadema onde a participação de alunos era menor.

As formas de seleção do diretor de escola, esfera estadual e municipal, estão sintetizadas nos Quadros 06 e 07:

Esfera estadual:

\begin{tabular}{|c|c|c|c|c|c|c|}
\hline Quadro 06: Caracterização da escolha do diretor, esfera estadual, dos municípios do Grande ABC - 2013 \\
\hline Cidade & $\begin{array}{c}\text { Seleção } \\
(\%)\end{array}$ & $\begin{array}{c}\text { Eleição } \\
\text { Apenas (\%) }\end{array}$ & $\begin{array}{c}\text { Seleção e } \\
\text { eleição (\%) }\end{array}$ & $\begin{array}{c}\text { Indicação } \\
\text { Técnica (\%) }\end{array}$ & $\begin{array}{c}\text { Indicação } \\
\text { Política (\%) }\end{array}$ & $\begin{array}{c}\text { Outras indicações e } \\
\text { Formas (\%) }\end{array}$ \\
\hline Santo André & 54 & 0 & 1 & 2 & 0 & 43 \\
\hline São Bernardo & 43 & 2 & 3 & 4 & 0 & 48 \\
\hline São Caetano & 30 & 0 & 0 & 10 & 0 & 60 \\
\hline Diadema & 40 & 4 & 0 & 0 & 0 & 56 \\
\hline Mauá & 54 & 0 & 0 & 0 & 0 & 46 \\
\hline Ribeirão Pires & 52 & 0 & 0 & 0 & 10 & 38 \\
\hline Rio Grande & 44 & 0 & 0 & 0 & 0 & 56 \\
\hline
\end{tabular}

Fonte: Elaboração dos autores.

O processo preponderante de escolha de diretor nos sete municípios, na esfera estadual, estava relacionada à seleção do profissional ou as outras formas de indicações. Ribeirão Pires era a única cidade que contava com indicações políticas e São Caetano com indicações técnicas.

Esfera municipal:

\begin{tabular}{|c|c|c|c|c|c|c|}
\hline Quadro 07: Caracterização da escolha do diretor, esfera municipal, dos municípios do Grande ABC - 2013. \\
\hline Cidade & $\begin{array}{c}\text { Seleção } \\
(\%)\end{array}$ & $\begin{array}{c}\text { Eleição } \\
\text { Apenas (\%) }\end{array}$ & $\begin{array}{c}\text { Seleção e } \\
\text { eleição (\%) }\end{array}$ & $\begin{array}{c}\text { Indicação } \\
\text { Técnica (\%) }\end{array}$ & $\begin{array}{c}\text { Indicação } \\
\text { Política (\%) }\end{array}$ & $\begin{array}{c}\text { Outras indicações e } \\
\text { Formas (\%) }\end{array}$ \\
\hline Santo André & 78 & 0 & 2 & 7 & 0 & 13 \\
\hline São Bernardo & 63 & 0 & 1 & 2 & 0 & 34 \\
\hline São Caetano & 16 & 0 & 0 & 47 & 11 & 26 \\
\hline Diadema & 7 & 13 & 7 & 40 & 0 & 33 \\
\hline Mauá & 0 & 0 & 100 & 0 & 0 & 0 \\
\hline Ribeirão Pires & 20 & 20 & 0 & 40 & 0 & 20 \\
\hline Rio Grande & - & - & - & - & - & - \\
\hline
\end{tabular}

Fonte: Elaboração dos autores.

No caso da esfera municipal, a escolha dos diretores era mais diversificada. Mauá, por exemplo, realizava o processo por meio de seleção e eleição (sistema misto). Em Santo André, o processo acontecia, de forma preponderante, por meio de seleção. A cidade de São Caetano apresentou o maior índice de indicação desses profissionais, sejam elas políticas, técnicas ou outras. Dados do Observatório de Educação do grande ABC, 2015, no entanto, mostraram que neste município a grande maioria dos 
profissionais assumia cargos por indicação política, contrariando os dados do Censo escolar de 2013. O que se pode deduzir é que no preenchimento do Censo, muitas vezes, por questões éticas não são realizadas as reais indicações de seleção dos profissionais da educação.

Os processos de elaboração do projeto político pedagógico, das sete cidades da região do Grande ABC, estão caracterizados nos Quadros 08 e 09.

Em relação à esfera municipal:

\begin{tabular}{|c|c|c|c|c|c|c|c|}
\hline Quadro 08: Processo de elaboração do PPP, esfera municipal, dos municípios da Região do Grande ABC - 2013 \\
\hline Cidade & $\begin{array}{c}\text { Modelo encaminhado } \\
\text { (secret. da educação) }\end{array}$ & $\begin{array}{c}\text { Elaborado pelo } \\
\text { diretor (depois } \\
\text { professores) }\end{array}$ & $\begin{array}{c}\text { Elaboração dos } \\
\text { professores e o } \\
\text { diretor escreveu }\end{array}$ & $\begin{array}{c}\text { Elaboração } \\
\text { Professores e } \\
\text { diretor }\end{array}$ & $\begin{array}{c}\text { Elaboração } \\
\text { colaborativa } \\
\text { (Prof., pais) }\end{array}$ & $\begin{array}{c}\text { Outra } \\
\text { forma de } \\
\text { elaboração }\end{array}$ & $\begin{array}{c}\text { Não } \\
\text { existe } \\
\text { PPP }\end{array}$ \\
\hline Santo André & 49 & 2 & - & 9 & 40 & - & - \\
\hline São Bernardo & 44 & 3 & 7 & 4 & 33 & 9 & - \\
\hline São Caetano & 37 & 16 & 5 & 21 & 11 & 10 & - \\
\hline Diadema & - & 13 & - & 20 & 60 & 7 & - \\
\hline Mauá & 100 & - & - & - & - & - & - \\
\hline Ribeirão Pires & 20 & - & - & - & 80 & - & - \\
\hline Rio Grande & 17 & 3 & - & 27 & 27 & 12 & 11 \\
\hline
\end{tabular}

Fonte: Elaboração dos autores.

Os processos de elaboração do PPP nos municípios eram bem variados. Em Santo André, São Bernardo, Mauá e Ribeirão Pires, eles ocorriam ou com um modelo enviado pela secretaria de educação ou de forma colaborativa. Na cidade de Rio Grande da Serra localizava-se o maior número de escolas sem tal documento. São Caetano tinha o menor índice de elaboração participativa (11\%) e o maior no modelo de elaboração do diretor, contando em outro momento com a participação dos professores. Em Ribeirão Pires, a elaboração era mais participativa do que em outros municípios.

Quanto à esfera estadual:

\begin{tabular}{|c|c|c|c|c|c|c|c|}
\hline \multicolumn{2}{|c|}{ Quadro 09: Processo de elaboração do PPP, esfera estadual, dos municípios da Região do Grande ABC -2013. } \\
\hline Cidade & $\begin{array}{c}\text { Modelo encaminhado } \\
\text { (secret. da educação) }\end{array}$ & $\begin{array}{c}\text { Elaborado pelo } \\
\text { diretor (depois } \\
\text { professores) }\end{array}$ & $\begin{array}{c}\text { Elaboração dos } \\
\text { professores e o } \\
\text { diretor escreveu }\end{array}$ & $\begin{array}{c}\text { Elaboração } \\
\text { Professores e } \\
\text { diretor }\end{array}$ & $\begin{array}{c}\text { Elaboração } \\
\text { colaborativa } \\
\text { (Prof., pais) }\end{array}$ & $\begin{array}{c}\text { Outra } \\
\text { forma de } \\
\text { elaboração }\end{array}$ & $\begin{array}{c}\text { Não } \\
\text { existe } \\
\text { PPP }\end{array}$ \\
\hline Santo André & 20 & 5 & 7 & 16 & 40 & 12 & - \\
\hline São Bernardo & 21 & 7 & 6 & 14 & 32 & 17 & 3 \\
\hline São Caetano & 20 & - & - & 10 & 50 & 10 & - \\
\hline Diadema & 16 & - & - & 10 & 54 & 16 & 2 \\
\hline Mauá & 21 & 7 & 2 & 16 & 48 & 3 & 3 \\
\hline Ribeirão Pires & 3 & 3 & - & 18 & 61 & - & - \\
\hline Rio Grande & 19 & 5 & 4 & 24 & 26 & 14 & 8 \\
\hline
\end{tabular}

Fonte: Elaboração dos autores.

Os processos de elaboração do PPP na esfera estadual estavam mais centralizados nos métodos participativos. Em todas as cidades, a elaboração aconteceu ou com os professores e diretores ou de forma colaborativa, envolvendo os vários atores. Em alguns municípios (São Bernardo, Diadema, Mauá e Rio Grande da Serra), as escolas ainda não contavam com este documento.

A participação da comunidade em atividades, eventos e campanhas na escola são descritas nos próximos quadros. O Quadro 10 mostra os espaços da unidade escolar que são utilizados para atividades comunitárias na esfera municipal:

Quadro 10: Espaços da escola utilizados para atividades comunitárias, esfera estadual, 2013. 


\begin{tabular}{|c|c|c|c|c|}
\hline Cidade & $\begin{array}{c}\text { Sim, planejadas } \\
\text { apenas pela escola. }\end{array}$ & $\begin{array}{c}\text { Sim, planejadas apenas } \\
\text { pela comunidade }\end{array}$ & $\begin{array}{c}\text { Sim, planejadas conjuntamente } \\
\text { (escola e comunidade). }\end{array}$ & $\begin{array}{c}\text { Não } \\
\text { Santo André }\end{array}$ \\
\hline São Bernardo & 23 & 11 & 59 & 16 \\
\hline São Caetano & 69 & 4 & 5 & 17 \\
\hline Diadema & 7 & - & 26 \\
\hline Mauá & - & - & 100 & 20 \\
\hline Ribeirão Pires & 20 & -- & 80 & - \\
\hline Rio Grande & - & - & - & - \\
\hline
\end{tabular}

Fonte: Elaboração dos autores.

A maioria das escolas das sete cidades realizaram atividades comunitárias, utilizando os espaços da unidade. Essas foram planejadas conjuntamente entre as escolas e a comunidade. Somente na cidade de São Caetano do Sul, o planejamento das ações foi mais centralizado na escola. No mesmo município, estava localizado o maior índice de não realização de atividades.

Quadro 11, esfera estadual:

\begin{tabular}{|c|c|c|c|c|}
\hline \multicolumn{6}{|c|}{ Quadro 11: espaços da escola utilizados para atividades comunitárias, esfera estadual, ABC -2013. } \\
\hline Cidade & $\begin{array}{c}\text { Sim, planejadas } \\
\text { apenas pela escola. }\end{array}$ & $\begin{array}{c}\text { Sim, planejadas apenas } \\
\text { pela comunidade }\end{array}$ & $\begin{array}{c}\text { Sim, planejadas conjuntamente } \\
\text { (escola e comunidade). }\end{array}$ & Não \\
\hline Santo André & 16 & 4 & 52 & 26 \\
\hline São Bernardo & 20 & 3 & 47 & 30 \\
\hline São Caetano & 30 & - & 60 & 10 \\
\hline Diadema & 23 & 3 & 51 & 23 \\
\hline Mauá & 27 & 3 & 55 & 15 \\
\hline Ribeirão Pires & 34 & 7 & 75 & 14 \\
\hline Rio Grande & 20 & 10 & 70 & 0 \\
\hline
\end{tabular}

Fonte: Elaboração dos autores.

A maioria das escolas das sete cidades planejavam atividades comunitárias, utilizando os espaços da unidade escolar, em conjunto, escolas e comunidade. No entanto, nesta esfera, o índice de não realização dessas atividades era maior do que na municipal.

O Quadro 12 traz, entre outras coisas, os eventos e a utilização da escola pela comunidade na esfera municipal:

\begin{tabular}{|c|c|c|c|c|c|c|}
\hline \multicolumn{3}{|c|}{\begin{tabular}{l|c|} 
Quadro 12: Eventos e a utllizaçao da escola pela comun \\
Ocorreram eventos da escola \\
destinados à comunidade (cursos, etc.)
\end{tabular}} & \multicolumn{2}{|c|}{$\begin{array}{c}\text { Ocorreram eventos da comunidade } \\
\text { usando instalações da escola }\end{array}$} & \multicolumn{2}{|c|}{$\begin{array}{c}\text { Ocorreram campanhas } \\
\text { propostas pela comunidade }\end{array}$} \\
\hline & Sim & Não & Sim & Não & Sim & Não \\
\hline Santo André & 78 & 20 & 64 & 36 & 20 & 80 \\
\hline São Bernardo & 79 & 21 & 67 & 33 & 10 & 90 \\
\hline São Caetano & 39 & 61 & 47 & 53 & 21 & 79 \\
\hline Diadema & 86 & 14 & 80 & 20 & 33 & 77 \\
\hline Mauá & 100 & 0 & 100 & 0 & 100 & 0 \\
\hline Ribeirão Pires & 60 & 40 & 60 & 40 & 20 & 80 \\
\hline Rio Grande & - & - & - & - & - & - \\
\hline
\end{tabular}

Fonte: Elaboração dos autores.

As escolas, em geral, criaram eventos destinados à comunidade, tais como cursos ou atividades esportivas. A comunidade utilizou as dependências e os recursos das unidades e, por fim, poucas campanhas de solidariedade foram propostas pela comunidade juntamente com a escola. A cidade de São Caetano do Sul foi aquela em que a comunidade participou menos dos eventos na escola.

No Quadro 13 verifica-se a esfera estadual:

Quadro 13: Eventos e a utilização da escola pela comunidade, esfera estadual, da Região do Grande ABC -2013. 


\begin{tabular}{|c|c|c|c|c|c|c|}
\hline & \multicolumn{2}{|c|}{\begin{tabular}{|c|} 
Ocorreram eventos da escola \\
destinados à comunidade (cursos, etc.)
\end{tabular}} & \multicolumn{2}{|c|}{$\begin{array}{c}\text { Ocorreram eventos da comunidade } \\
\text { usando instalações da escola }\end{array}$} & \multicolumn{2}{|c|}{$\begin{array}{c}\text { Ocorreram campanhas } \\
\text { propostas pela comunidade }\end{array}$} \\
\hline & Sim & Não & Sim & Não & Sim & Não \\
\hline Santo André & 51 & 49 & 53 & 47 & 21 & 79 \\
\hline São Bernardo & 60 & 40 & 51 & 49 & 30 & 70 \\
\hline São Caetano & 50 & 50 & 60 & 40 & 20 & 80 \\
\hline Diadema & 61 & 39 & 51 & 49 & 30 & 70 \\
\hline Mauá & 68 & 32 & 55 & 45 & 34 & 66 \\
\hline Ribeirão Pires & 59 & 41 & 54 & 46 & 21 & 79 \\
\hline Rio Grande & 90 & 10 & 60 & 40 & 20 & 80 \\
\hline
\end{tabular}

Fonte: Elaboração dos autores.

Os dados das escolas da esfera estadual são bem similares aos da municipal. Em geral, as unidades escolares criaram eventos destinados à comunidade, que utilizou as instalações e os recursos das escolas, e poucas campanhas de solidariedade foram propostas.

\section{Contextualização dos resultados a partir da perspectiva dos diretores de escola}

Dos resultados encontrados, a partir do Censo Escolar de 2013, as questões relativas ao conselho de escola e ao Projeto Político Pedagógico foram analisadas a partir da visão de um grupo de diretores das sete cidades da região do grande ABC. A consistência, a pouca diversidade e a recorrência dos depoimentos coletados possibilitaram que os dados fossem agrupados e analisados de forma geral. Tal situação, na análise, possibilitou um entendimento mais amplo e não particularizado por município.

Em relação à formação dos conselhos de escolas foi possível agrupar os dados em dois grupos, independente do município: aqueles em que os atores (pais, professores) se candidatavam para participar deste colegiado e, neste particular, era realizada algum tipo de eleição para compor o grupo, e aqueles em que, em geral, os diretores indicavam as pessoas para a participação e, neste caso, havia algum tipo pleito, mas direcionado. Destaca-se que neste segundo tipo de formação, os diretores sinalizaram que ele ocorre "por causa da baixa participação dos pais nas atividades da escola” (DIRETOR, 12). Em algumas situações, como indicado, se este procedimento não for adotado a formação do conselho fica comprometida.

Os conselhos tinham a função consultiva e deliberativa, segundo os depoentes. O tema mais tratado, nas reuniões ordinárias ou extraordinárias e, em muitos casos o único, estava atrelado à indisciplina dos alunos. Em algumas escolas, o tema dos encontros como disse um diretor de São Caetano do Sul "era sempre o mesmo, indisciplina dos alunos" (DIRETOR, 21).

O tema indisciplina tratado nos conselhos, segundo os diretores, tinha uma gradação bem variada: indisciplina na sala de aula, o que afeta outros alunos e desorienta os professores; depredação ou pichação da escola, afetando o patrimônio público; ameaças, ofensas ou agressões ao professor, funcionário ou a outro aluno, causando inconveniências; violência entre alunos, brigas dentro ou fora da escola; consumo de álcool e drogas na unidade escolar, espalhando medo; estudantes que tomavam algum tipo de medicação e causavam distúrbios na escola. Em relação às decisões do colegiado para lidar com tais situações, pode-se afirmar que elas eram bem diversas: orientações aos familiares do aluno, indicação do caso para o conselho tutelar ou para a polícia e sugestão da transferência do jovem de escola. 
Em relação ao PPP, de forma geral, os participantes deste estudo sinalizaram a importância deste para orientar as ações e decisões na escola. Foi comum ouvir relatos nas entrevistas da relevância do PPP para melhorar, entre outras coisas, a participação dos professores nas atividades escolares, os resultados da escola, a gestão escolar: “o PPP é importante para o planejamento da escola, quem quer qualidade tem de pensar nele, tem de planejar" (DIRETOR, 06).

Há em algumas escolas, muito mais que outras, um discurso bem consolidado sobre este Projeto. No entanto, na realidade foi constatado, na maioria dos casos pela opinião dos diretores, que o documento era pouco conhecido pelas pessoas que atuavam na escola e pelos membros do conselho (os conselheiros não tinham cópia do documento). Aqueles que conheciam o PPP, tinham poucas referências sobre seu conteúdo, sendo que o mesmo era muito pouco revisitado ao longo do ano, não era monitorado e não norteava as discussões e decisões na unidade escolar. Somente em duas escolas, uma de Mauá e outra de Diadema, o documento tinha significado e concretude em algumas ações e decisões das unidades. Tal fato pode ser explicado pela formação e pela experiência dos diretores, ambos com ligações com universidades e movimentos populares.

\section{Discussão dos resultados}

O grupo de diretores da região era formado em sua imensa maioria por mulheres, tanto na esfera municipal como estadual, brancas, com idade acima dos 40 anos, e em algumas cidades, mais de 40\% da força de trabalho estava acima dos 50 anos, formadas em Pedagogia, em instituições privadas, em cursos presenciais, com algum tipo de pós-graduação, especialização de 360 horas, com experiência na gestão da escola e com uma carga horária média de trabalho de 40 horas semanais.

Destaca-se deste perfil a formação superior desses profissionais em cursos superiores e o fato de a maioria possuir algum tipo de pós-graduação e experiência. Exceto as cidades de Santo André, Diadema e Riberião Pires, escolas municipais, a grande maioria dos diretores possuía mais de cinco anos de experiência na profissão. De fato, a experiência é uma característica importante, pois, como afirmaram Béteille, Kalogrides e Loeb (2011), alunos apresentam maior desempenho em escolas onde os diretores possuem maior experiência.

Neste cenário, destacam-se algumas preocupações para a região. Em primeiro lugar, o fato da grande maioria dos diretores ter menos de cinco anos de efetivo exercício na mesma escola, situação que colide com dados que mostram que diretores que estão a mais tempo no cargo, entre 5 a 15 anos, influenciam mais positivamente o rendimento dos alunos (PEREDA; LUCCHESI, 2015). Em segundo lugar retratase a questão de que uma grande parte desses diretores poderá se aposentar nas próximas décadas e com eles um corpo de conhecimentos práticos, experiências de resolução de problemas e conflitos e formas de gerenciamento da escola, entre outros. Conhecimentos e experiências que são adquiridos e desenvolvidos na prática por meio da ação e da reflexão e que não são passíveis de serem alcançados na formação inicial. 
A experiência, aliada à reflexão e à ação, é fundamental para o profissional adquirir e desenvolver competências. O especialista difere do principiante na organização do conhecimento em torno de modelos mentais e não somente em função do enunciado dos problemas, e para tal precisa da experiência como elemento catalizador da aprendizagem. (LE BOTERF, 2003). A experiência é um elemento formador do gestor escolar competente. À medida que ele desenvolve ações competentes vai, ao mesmo tempo, acumulando a confiança de sua comunidade que lhe permite trabalhar com mais tranquilidade e assumir riscos. Tal situação permite a ele inovar e ampliar sua especialização.

Em relação à gestão democrática, a grande maioria das escolas dos sete municípios possuíam os canais desejados para sua realização como sinalizou Araújo (2009): a participação da comunidade, escolha de dirigentes, conselho escolar, conselho de classe, grêmio estudantil, Projeto Político Pedagógico (São Caetano contava menos com o PPP). Tal situação mostra avanço em relação aos dados do Censo Escolar de 2011, onde somente um pouco mais da metade possuíam tais canais.

Na região do $\mathrm{ABC}$, todas as unidades escolares possuíam conselho de escola, em ambas as esferas, com a participação ampla de professores, funcionários, alunos e pais. Neste sentido, as escolas realizavam mais de três reuniões ao longo do ano. No entanto, esses colegiados não eram, como afirmaram Azevedo e Gracindo (2005), instrumentos para a prática democrática, representando os interesses da escola e auxiliando nas tomadas de decisões de natureza administrativa, financeira e político-pedagógicas.

$\mathrm{Na}$ formação deste colegiado, destaca-se que um grupo, apesar da justificativa de falta de participação, era indicado pelos diretores o que difere da participação espontânea. Neste caso, como indicam alguns autores (BORDIGNON; GRACINDO, 2001) se eternizam os processos de participação como colaboração de mão única, de adesão e de subordinação à direção da escola, onde as decisões são previamente acordadas e tomadas antecipadamente sem a participação de todos. Tal situação diminui a possibilidade de o participante influenciar as decisões da escola e gera menos compromisso.

Nas reuniões dos conselhos, o tema mais tratado relacionava-se à indisciplina dos alunos. Tal situação contraria, de acordo com Gracindo (2009), a ideia de que este colegiado tem de auxiliar nas tomadas de decisões de natureza administrativa, financeira e político-pedagógicas. Neste particular, reduz-se a capacidade de auxílio do conselho à gestão escolar.

O processo de seleção dos diretores nos sete municípios, na esfera estadual, estava relacionado à seleção do profissional ou as outras formas de indicações. Na esfera municipal, essa seleção era mais diversificada. $\mathrm{Na}$ cidade de São Caetano do Sul, esfera municipal, situavam-se as escolas que criavam menos possibilidades de participação para a comunidade, eram mais centralizadoras e apresentavam um menor número de reuniões do conselho de escola no ano. Este município caracterizou-se também por possuir, na seleção de diretores, o maior índice de indicação política de profissionais. Resultado que se torna inquietante, considerando aquele que sinaliza que a indicação política de gestores tem efeito negativo nos resultados do IDEB (MIRANDA; PAZELLO, 2014). 
O PPP, apesar de existir nas escolas e já ser parte do discurso dos diretores, ele não era reconhecido como um documento coletivo e formatado pela realidade escolar e de seu entorno. As intensões declaradas no projeto não eram revisadas nos momentos de discussões e tomadas de decisões na escola. Ele não orientava os projetos educacionais e as práticas pedagógicas e não se constituía em um compromisso para a formação o cidadão (VEIGA, 2003; 2004).

O PPP é o documento que baliza a missão e os valores da escola e o tipo de formação que se acredita, ou seja, a identidade da instituição. Desta forma, as discussões, ações e decisões administrativas e pedagógicas devem ser alicerçadas em suas bases, incluindo as decisões que são tomadas pelo conselho de escola. Tais premissas não foram validadas, pelo menos nas escolas as quais os diretores foram entrevistados. Nas escolas investigadas, o PPP apresentava pouco sentido emancipatório (VEIGA, 2003) caracterizado por um processo de vivência democrática.

O que se pode depreender desses dados, em relação ao conselho escolar e ao PPP, é o fato de que os diretores ainda não se sensibilizaram sobre as possibilidades de auxílio destes, tanto na condução como na proposição de projetos de melhorias na busca da qualidade escolar. Ou seja, da capacidade de fortalecimento da escola com estas instâncias, atuando colaborativamente.

\section{Considerações Finais}

Compreender o perfil dos diretores e as formas de condução da gestão democrática na região do grande ABC Paulista fornece indicações relevantes para os gestores e especialistas em educação para a idealização e concretização de planos de trabalho, considerando que as características (perfil) e a GD são condições estruturantes para a qualidade da educação, pois possibilitam, entre muitas coisas, que a escola crie vínculos com a comunidade. Paralelamente, os achados desta pesquisa podem ser levados para os cursos de formação continuada de gestores escolares, promovendo o debate sobre os temas.

O fato de os diretores, no perfil, apresentarem experiência profissional na gestão escolar caracteriza-se como um fator positivo e importante para o desempenho dos alunos. No entanto, tal experiência não foi totalmente acumulada na mesma escola. Há ainda outra preocupação que se relaciona à questão da aposentadoria de muitos diretores nas próximas décadas (diretores experientes no gerenciamento da escola). Neste sentido, os municípios, por meio do Consórcio Intermunicipal da região, poderiam propor a criação de um programa que pudesse captar um pouco do conhecimento e da experiência acumuladas por esses profissionais que ainda estão na ativa, próximo de se aposentarem. As secretarias de educação poderiam promover encontros entre eles para a criação de materiais, seguidos de orientações para aqueles que ingressarem na gestão escolar. Ao mesmo tempo, videoaulas poderiam ser gravadas, incorporando um pouco das ideias e das recomendações desses profissionais como uma estratégia para o desenvolvimento de recursos humanos especializados. Os diretores novos não teriam de "reinventar a roda" e aproveitariam das experiências daqueles que viveram alguns anos naquela escola. Neste caso, o diretor deixaria a função, mas parte de suas experiências e conhecimentos permaneceriam na escola. 
Já em relação à gestão democrática, conduzida pelos diretores nas escolas, acredita-se que esta tem ainda um longo percurso para se concretizar. Seus ideais estão mais consolidados no papel e no discurso do que na concretude do cotidiano escolar. Tal situação pode ser explicada pelo fato, como afirmaram Bordignon e Gracindo (2001), de a GD exigir mais do que algumas simples mudanças nas estruturas organizacionais ou na criação de canais de participação. De fato, ela requer uma mudança de paradigma, fundamentando a construção de uma nova proposta educacional. Na região, nas escolas analisadas, podese dizer que ela é ainda uma metáfora a ser perseguida, que inspira os diretores, mas incita pouco à reflexão coletiva, a participação e a tomada de decisão. Espera-se, no entanto, que esse quadro seja alterado com a promulgação e implementação do PNE, pois a meta 19 visa assegurar condições para que em dois anos seja efetivada a gestão democrática nas escolas brasileiras.

\section{Referências Bibliográficas}

ARAUJO, A. C. Gestão democrática da educação: a posição dos docentes. 2000. 220 f. Dissertação (mestrado) Faculdade de Educação, Universidade de Brasília, Brasília.

- A gestão democrática e os canais de participação dos estudantes. Revista Retratos da Escola, Brasília, v.3, n. 4, p. 253-266, jan./jun. 2009.

AZEVEDO, J. M. L.; GRACINDO, R. V. Educação, sociedade e mudança. Brasília: CNTE, 2005.

BARROS, R.P.; MENDONÇA, R. O impacto de três inovações institucionais na educação brasileira. Rio de Janeiro: IPEA, 1998.

BÉTEILLE, T.; KALOGRIDES, D.; LOEB, S. Stepping stones: Principal career paths and school outcomes. NBER Technical Report, 2011.

BIONDI, R. L.; FELÍCIO, F. Atributos Escolares e o Desempenho dos Estudantes: uma Análise em Painel dos

Dados do SAEB. Brasília: INEP, 2007.

BORDIGNON, Genuíno; GRACINDO, Regina Vinhaes. Gestão da educação: o município e a escola. In: FERREIRA, Naura S. Carapeto; AGUIAR, Márcia (Org.). Gestão da educação: impasses, perspectivas e compromissos. São Paulo: Cortez, 2001.

BRASIL. Constituição da República Federativa do Brasil de 1988. Brasília: Presidência da República, Casa Civil, 1988. Disponível em: http://www.planalto.gov.br/ccivil_03/Constituicao/Constituiçao.htm. Acesso em: 13 jul. 2014.

Lei $\mathbf{n}^{\circ}$ 9.394, de 20 de dezembro de 1996. Estabelece diretrizes e bases da educação nacional. Diário Oficial [da] República Federativa do Brasil, Brasília, 23 de dez. 1996.

CORBIN, J.; STRAUSS, A. Basics of qualitative research: techniques and procedures for developing grounded theory. 2 ed. London: Sage Publications, 1998.

CURY, C. R. J. Formação em política e administração da educação no Brasil. Congresso Luso-brasileiro de Política e Administração da Educação, n. 2, 2001.

Gestão democrática da educação: exigências e desafios. Revista Brasileira de Política e Administração da Educação, São Bernardo do Campo, v. 18, n. 2, jul./dez. 2002.

DOBBIE, W.; FRYER, R. Getting Beneath the Veil of Effective Schools: Evidence from New York City. 2013.

DOURADO, L. F.. A escolha de dirigentes escolares: políticas e gestão da educação no Brasil. In: FERREIRA, Naura Syria Carapeto. Gestão democrática da educação: atuais tendências, novos desafios. 2. ed. São Paulo: Cortez, 2000. p. 77-95.

DOURADO, L. F.; OLIVEIRA, J. F. A qualidade da educação: perspectivas e desafios. Cad. CEDES, Campinas, v. 29, n. 78, p. 201-215, 2009.

OBSERVATÓRIO DA EDUCAÇÃO DO GRANDE ABC. Relatório do primeiro trimestre. Universidade Municipal de São Caetano do Sul. 2015

FULLAN, M. Stratosphere: Integrating technology, pedagogy and change knowledge. Toronto: Pearson, 2013. The Principal: Three keys to maximizing impact. San Francisco: Jossey-Bass, 2014.

GARCIA, P. S.; PREARO, L. L. C.; ROMERO, M. C.; BASSI, M. S. A Infraestrutura das Escolas de Ensino Fundamental da Região do Grande ABC Paulista. Revista Ibero-Americana de Estudos em Educação, v. 9, p. 614-631, 2014.

GRACINDO, R. V. O gestor escolar e as demandas da gestão democrática: exigências, práticas, perfil e formação. Revista Retratos da Escola, Brasília, v.3, n. 4, p. 135-147, jan./jun. 2009.

GRISSOM, J. A., LOEB, S., \& MASTER, B. Effective Instructional Time Use for School Leaders: Longitudinal Evidence from Observations of Principals. Educational Researcher, v. 42, n. 8, p. 433-444, 2013.

LE BOTERF, G.. Desenvolvendo a competência dos profissionais. 3. ed. Porto Alegre: Artmed; Bookman, 2003.

LÜCK, H. Concepções e processos democráticos de Gestão Educacional. $3^{\mathrm{a} e d}$ Petrópolis: Vozes, 2008. 
MARIONI, L.; FREGUGLIA, R. S.; COSTA, A. B. M. Impacts of school management on educational development: a longitudinal analysis from the teacher's perspective. ANPEC, 2014.

MENEZES FILHO, N. Os Determinantes do desempenho escolar do Brasil. São Paulo: Instituto Futuro Brasil/IBMEC, 2007.

MIRANDA, J. G.; PAZELLO, E. T. Rotatividade de Diretores e Desempenho da Escola. SBE, 2014.

PARO, V. H. Gestão democrática da escola pública. 3 ed. São Paulo: Ática, 2006.

PEREDA, P.; LUCCHESI, A. O Processo de Seleção de Diretores nas Escolas Públicas Brasileiras. Relatório de Avaliação Econômica. Fundação Itaú Social, 2015.

SOARES NETO, J. J.; JESUS, G. R.; KARINO, C. A.; ANDRADE, D. F.OARES NETO, J. J. Uma escala para medir a infraestrutura escolar. Estudos em Avaliação Educacional, São Paulo, v.24, n.54, p.78-99, jan./abr. 2013.

VEIGA, I. P. A. (Org.) Projeto Político Pedagógico - Uma Construção Possível. Campinas, SP: Papirus, 1997. . Inovações e projeto político-pedagógico: uma relação regulatória ou emancipatória? Cad. Cedes, Campinas, v. 23, n. 61, p. 267-281, dezembro 2003.

Educação básica e educação superior: projeto político-pedagógico. 3. Ed. Campinas: Papirus, 2004.

VIANNA, I. O. A. Planejamento Participativo na Escola. São Paulo: EPU, 1986.

YIN, Robert. Aplications of case study research. Thousand Oaks: SAGE Publications, 1993. 